\title{
تحديد التوزيع الاحتمالي المناسب لتسعير تأمين الائتمان الزراعي في مصر المبن
}

\author{
د. نها عبد اللطيف عبد الحميد شاهين

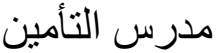 \\ بقسم الرياضة و الاحصاء و التأمين \\ كلية التجارة جامعة كفر الثيخ
}

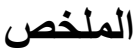

يلعب الائتمان الزراعي دوراَ هامأ ومتز ايداً في إحداث استمرار التنمية الزراعية

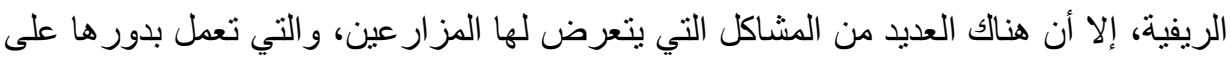

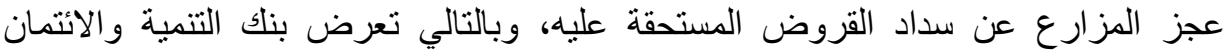
الزر اعي للخسائر ، و الحد من قدرته على منح مزيد من الايتمان للمز ارعين.

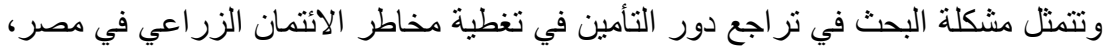

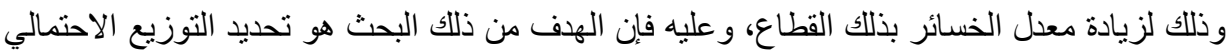

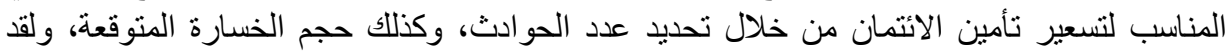

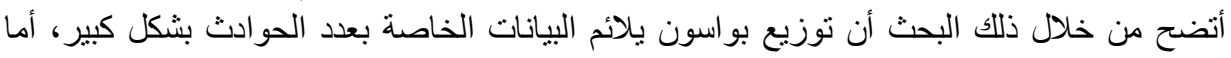
التوزيع الملائم لتقدير حجم الخسائر المنوقعة فكان التوزيع اللو غاريتمي الطبيعي.

\section{The Identification of the suitable probability distribution for the pricing of agricultural credit insurance in Egypt}

\footnotetext{
Abstract

The agricultural credit plays a very important and excessive role in making progress for the rural agricultural development. But there are several problems that face the farmers and make the farmer unable to repay his deserved loans therefore the development and credit bank will get loss and will not able to grant more credit for the farmers.

The problem of this thesis is the decline of the role of the credit in covering the risks of agricultural credit in Egypt because of the increase of the rate of the loss in
} 
this sector therefore the purpose of this thesis is the identity of the suitable probability distribution for the pricing of credit insurance through the identification a number of accidents also the volume of the expected loss Through this thesis it has been shown that Poisson Distribution was more suitable for the private data for a number of accidents But The log - normal Distribution was the suitable for the evaluation of the volume of the expected loss.

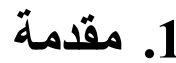

يلعب القطاع الزر اعي دورأ حيويـاً وهامـأ في اقتصـاديات الدول الناميـة

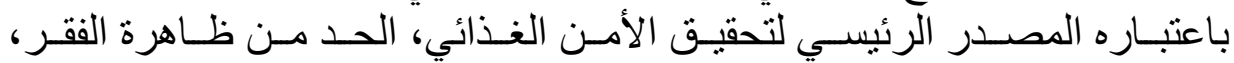

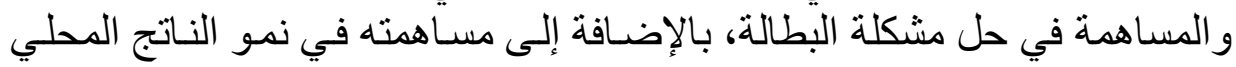

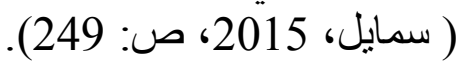

ويعتبر توفير التمويل للقطاع الزر اعي دعامة أساسية للنهوض بالإنتاج

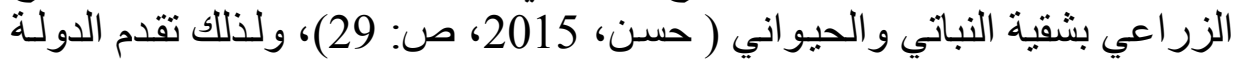

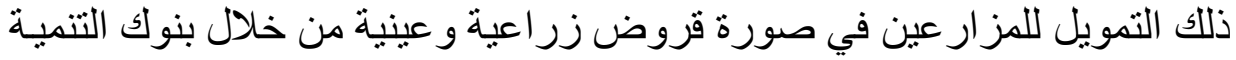

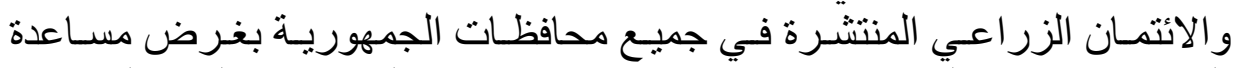

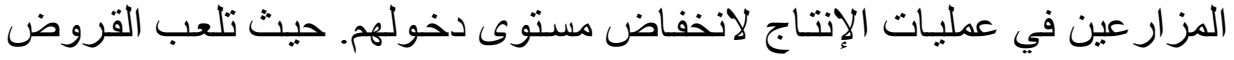

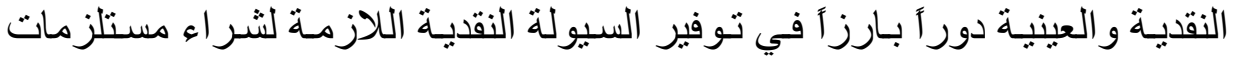

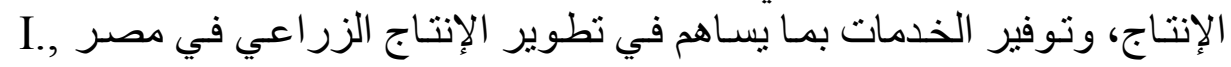
.( Saddik 1995 )

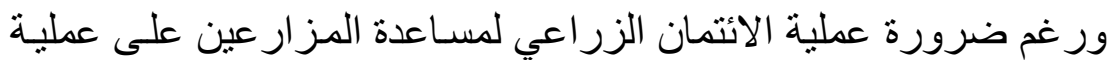

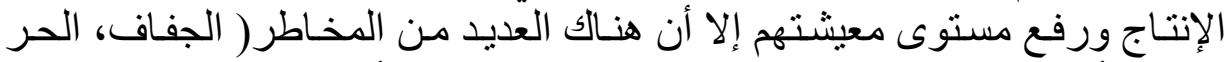

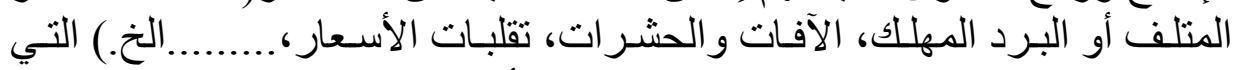

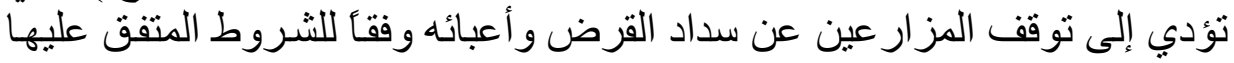

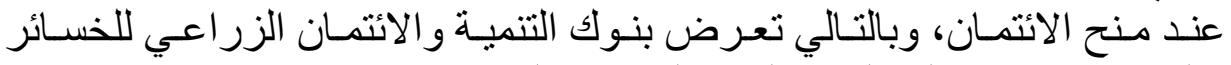

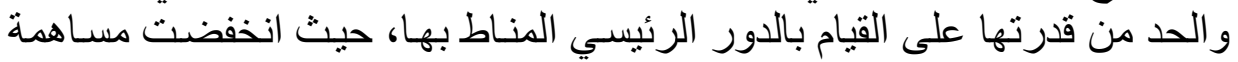

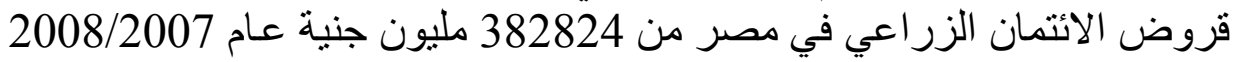

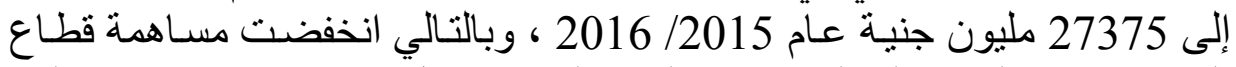

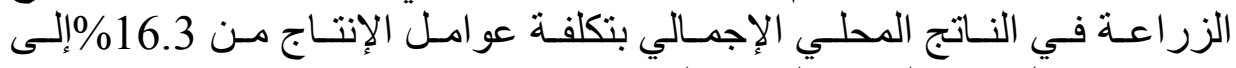
11.7\% خلال نفس الفترة (الجهاز المركزي: 2017). 


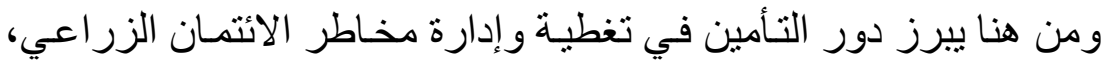

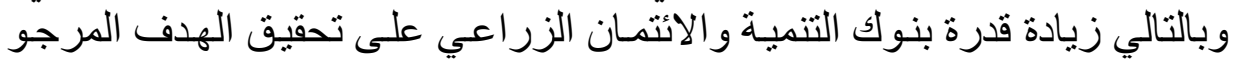
من إنشائها.

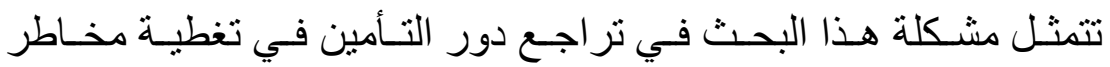

\section{(1-1) مشكلة البحث هن:}

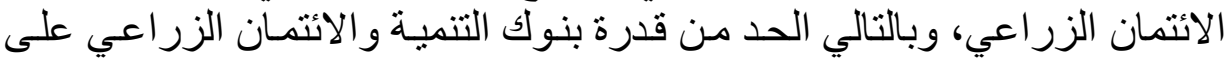

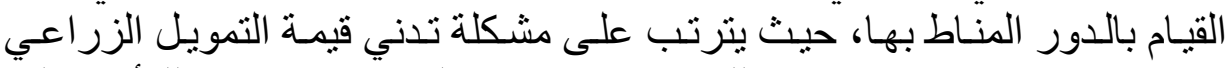

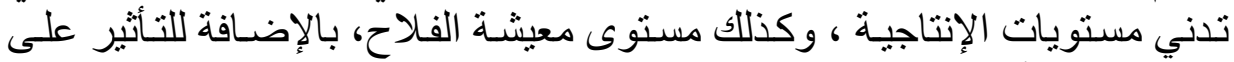

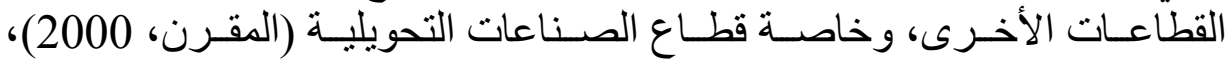

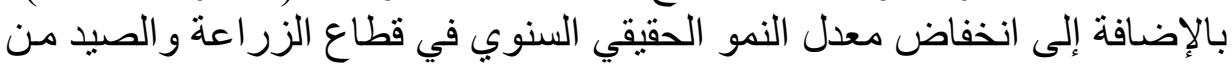

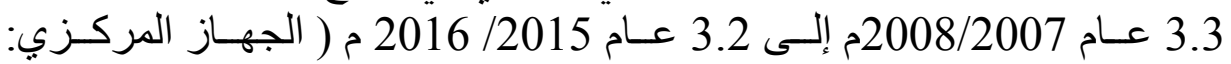

ويرجع سبب تراجع دور شـركات التأمين في تغطيـة مخـاطر الاتئهـان

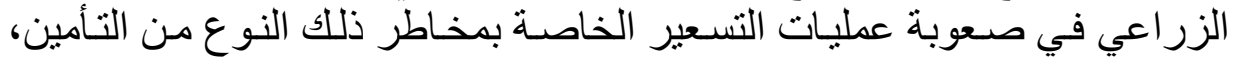
و هو مكان هدفأ من ذللك البحث.

\section{(2-1) هدف البحث}

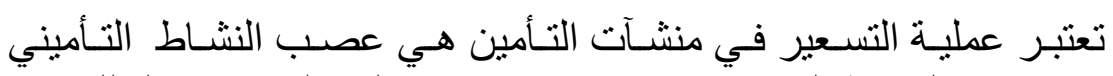

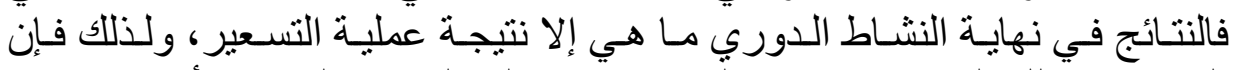

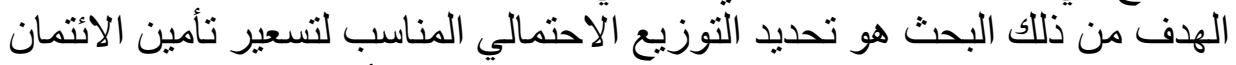

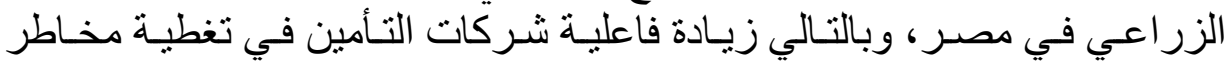

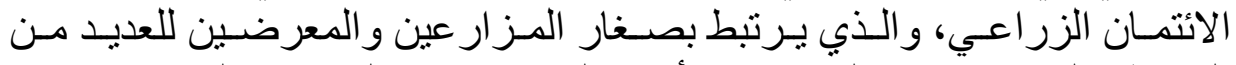

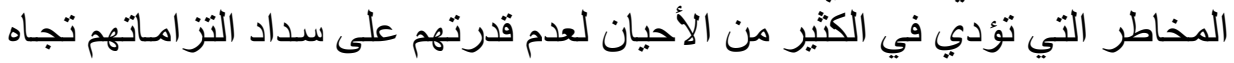

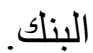

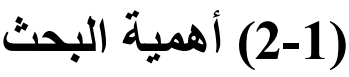

يعتبر الانتمـان الزراعي أحد الأدوات الهامة والأساسية لدعم واستمرار

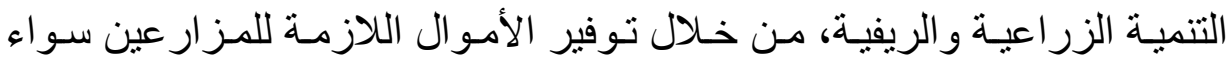

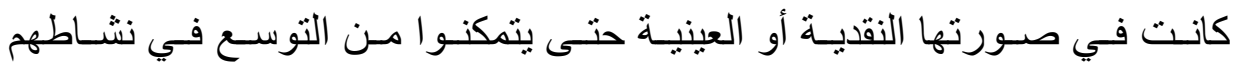

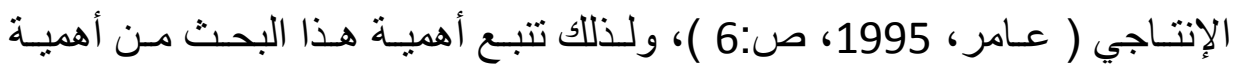


التأمين علي مخاطر الائتمـان الزراعي لكافة الأطر اف، و المتمثلة في المؤمن،

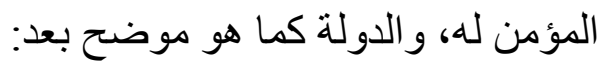

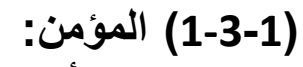

- - وضع أسس سليمة لتسعير تأمين مخاطر الايتمان الزراعي. - يادة دور شركات التأمين في مساندة مشاريع دعم الاقتصاد القومي.

(2-3-1) (المؤمن له:

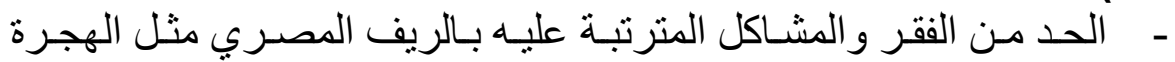

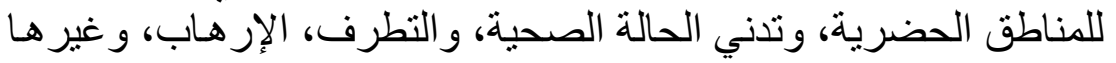

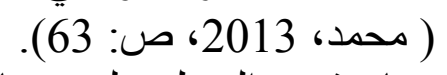
- زيادة قدرة البنوك على مسـاعدة صنغار المزارعين في تمويل إنتاجيتهم

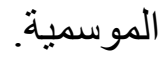

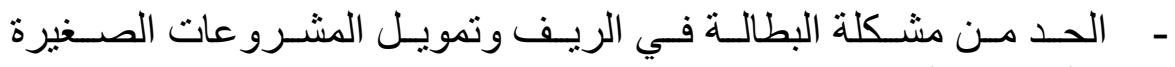
و المتناهية الصغر. (3-3-1) (الدولة:

- - - زيادة الناتج الزراعي القومي، وزيادة الإستثمار في المجال الزراعي.

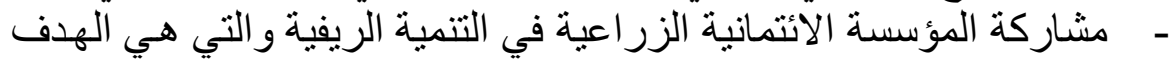

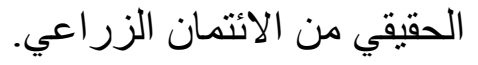

\section{(4-1) - (الدراسات السابقة}

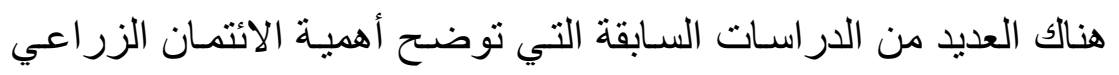

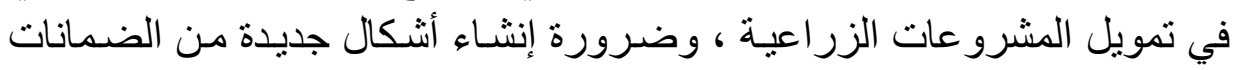

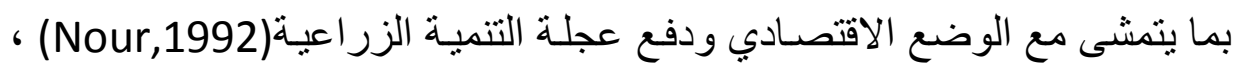

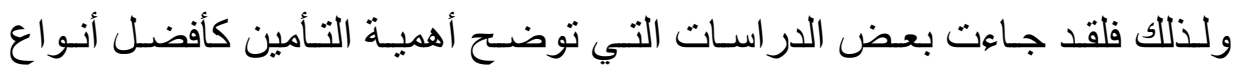

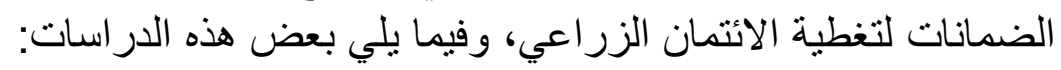


(1-4-1) دراسة (Asseldonk V., et al , 2018)

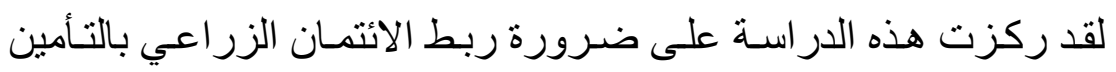

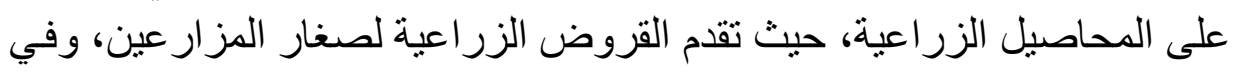

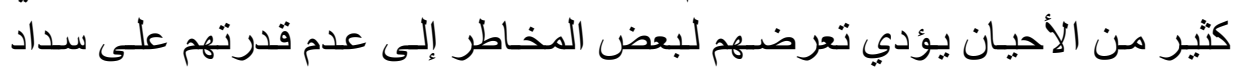

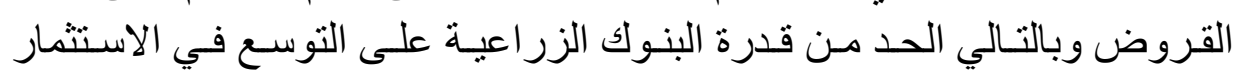
الزر اعي خاصة في الدول النامية.

ولقد توصلت تلك الدراسة إلى أن ربط الايتمان بالتأمين على المحاصيل

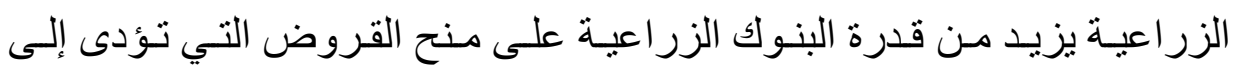

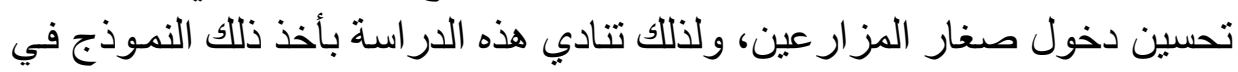

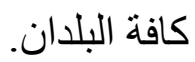

(2-4-1) (20)

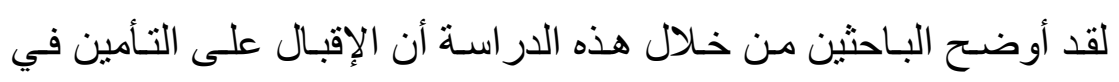

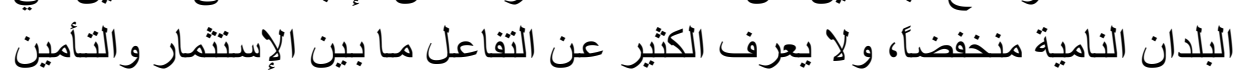

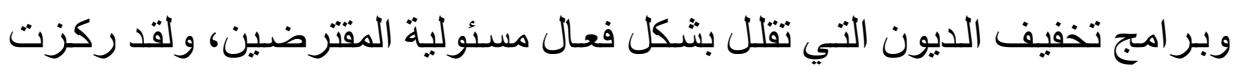

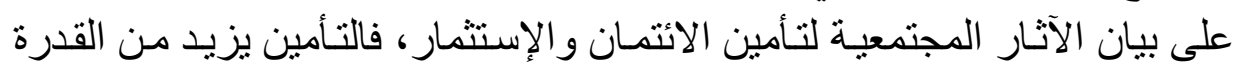
على منح الائنمان.

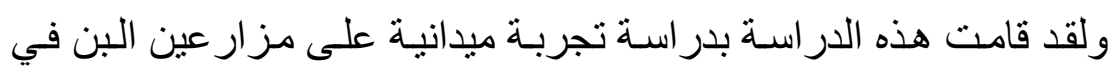

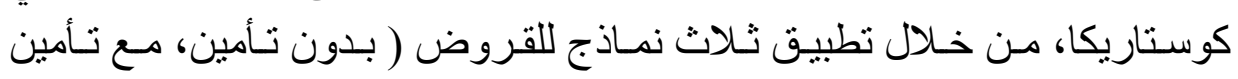

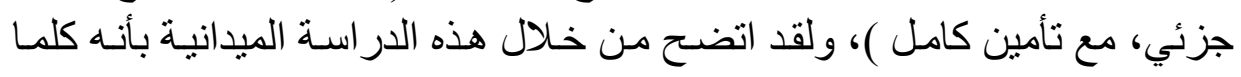

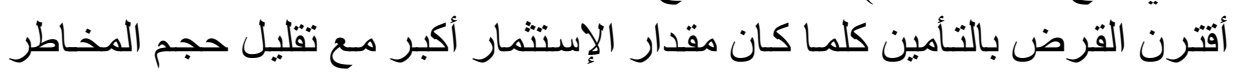

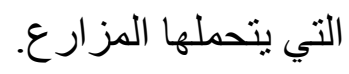


(Carter \& Cheng, 2016) دراسة)

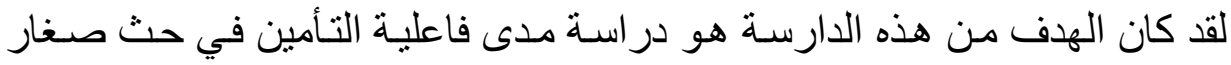

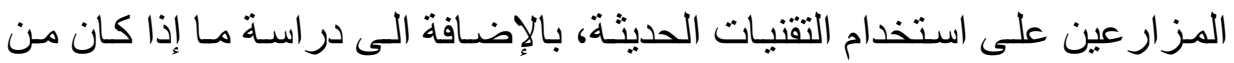
الأفضل تقديم التأمين كعقد بمفرده أو تقديمة كعقد مرتبط بعقد الالتمان.

$$
\text { ولقد توصلت لعدة نتائج أهمها : }
$$

1- أن التأمين على المحاصيل الزراعيـة يغطي معظم المخـاطر التـي

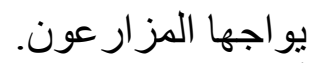
2- أن التر ابط ما بين التأمين والاتيتمان له عدة إيجابيات أهمها استقرار

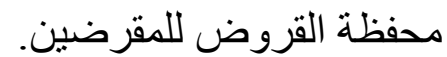
3- أن التأمين يكون أكثر فاعلية في البيئات الغير مرتفعة المخاطر و التي تستخدم تقنيات حديثة.

(Carter A., 2006 (4-4-1)

لقد ركزت هذه الدراسـة على أهمية التأمين كوسيلة للتوسع في الالتئمان

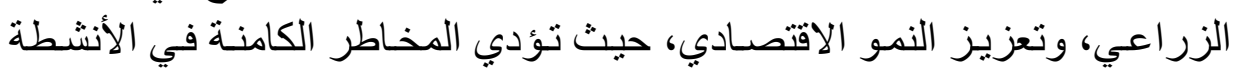

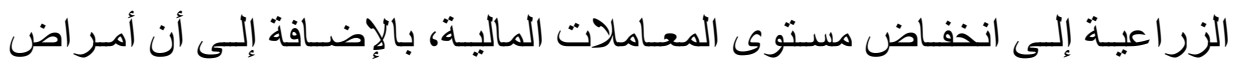

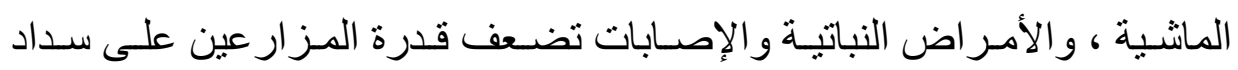

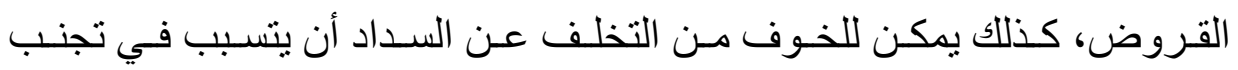

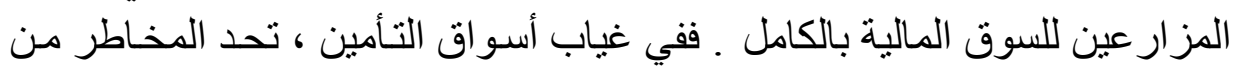

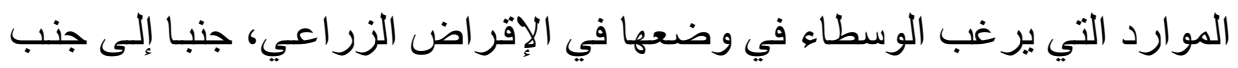
مع خطر ارتفاع التكاليف التي تقلل الطلب على التع الايتمان.

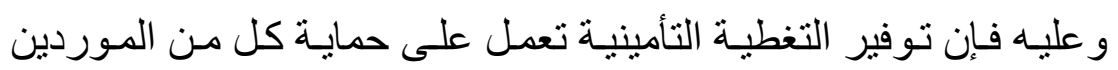

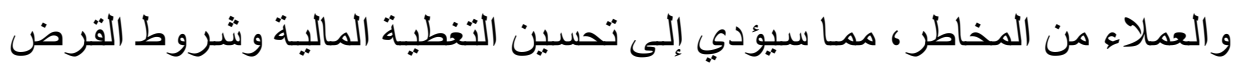

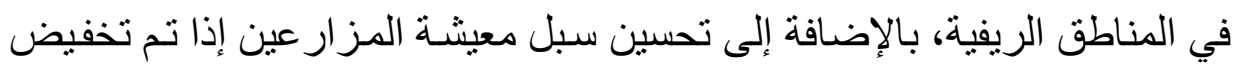

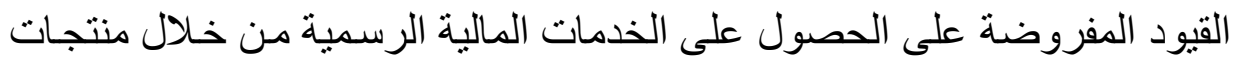

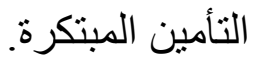


(Carter M., et al, 2007 ) دراسة)

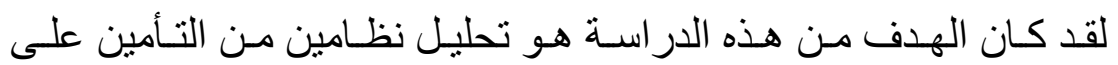

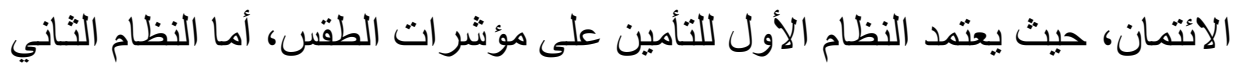

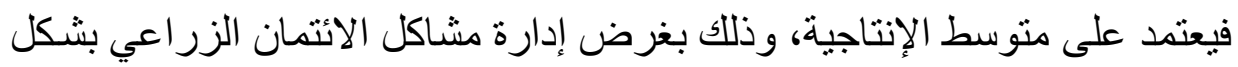

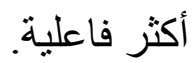

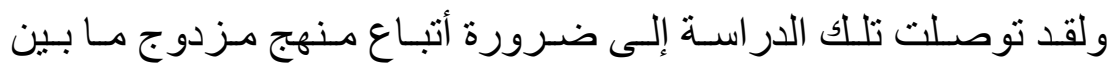

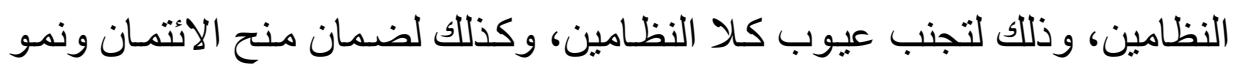

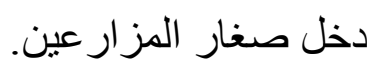

\section{(5-1) خطة البحث}

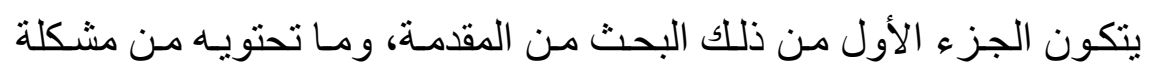

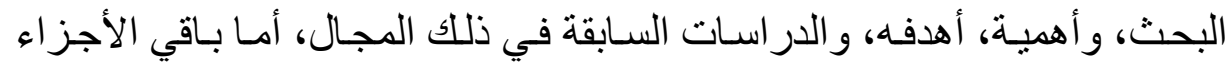

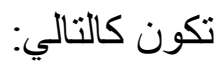
الجزء الثاني : مشاكل الانتمان الزر اعي في مصر . ل

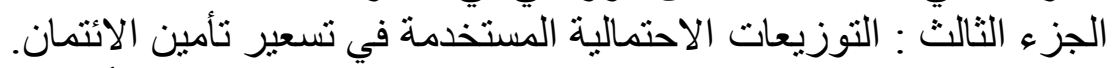

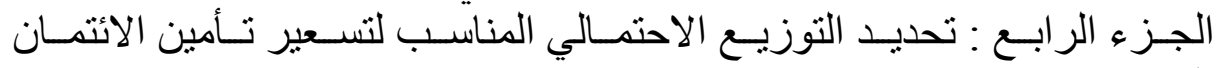

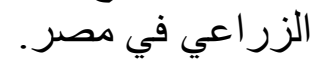

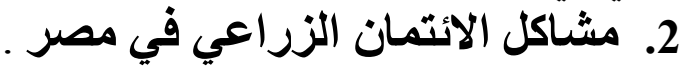

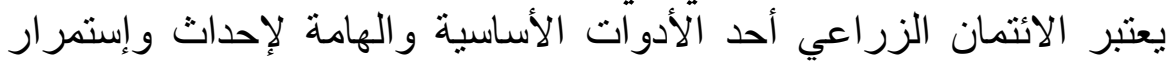

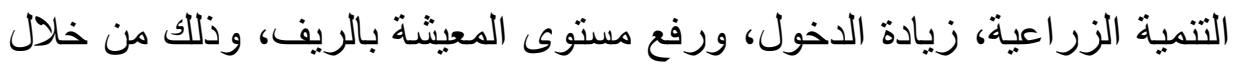

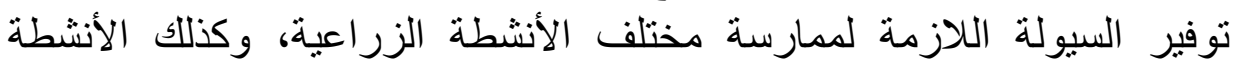

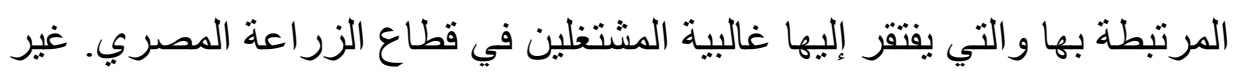

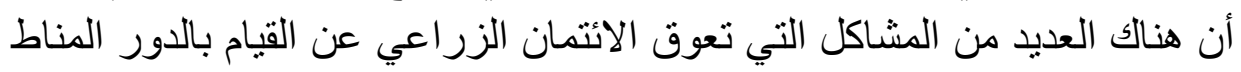
به كما ينبغي، وتتمثل تللك المشاكل فيما يلي:

1- صعوبة الاجر اءات وكثرة الضمانات اللازمة للحصول على الائتمان.

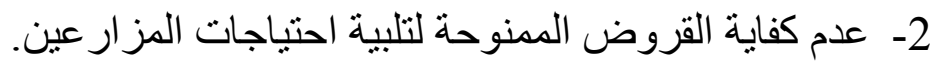

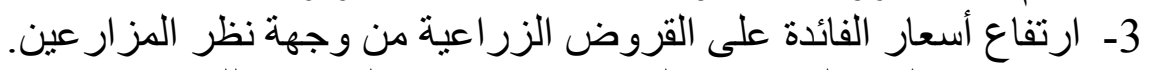

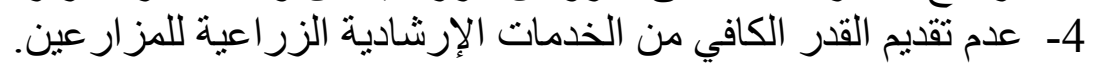


5- عدم مقدرة معظم المزار عين على الالتز ام بسداد القرض في مو عده.

وسنتناول تللك المشاكل بالثرح فيما يلي:

(2- 1) صعوبة الاجراءات والتشدد في الضمانات اللازمة للحصول على الائتمان.

يواجه المزارعون العديد من الاجراءات الروتينية المعقدة والأوراق

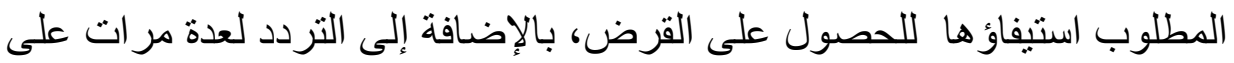

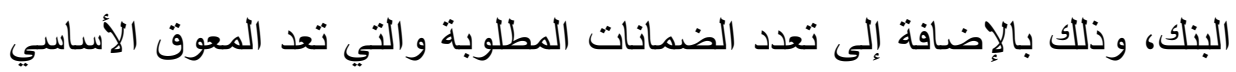
الذي يعوق صغار المزارعين من الحصول على احتياجاتهم الأساسية لمزاولة

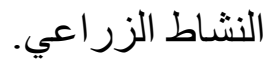

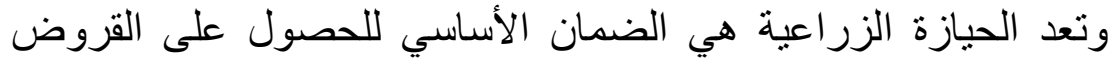

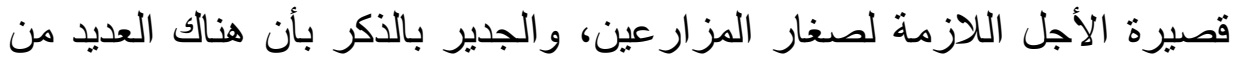

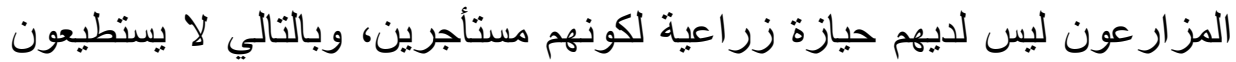

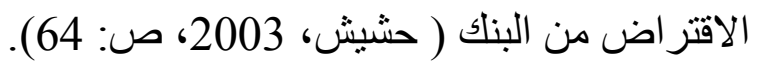

(2- 2) عدم كفاية القروض الممنوحة لتلبية احتياجات المزارعين.

يتم صرف القروض القصيرة الأجل بصفة عامة بنسبة 70\% كحد أقصى

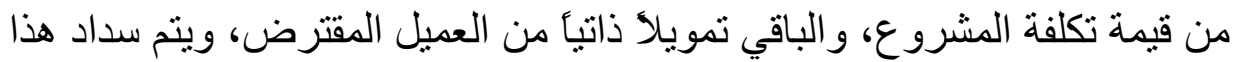

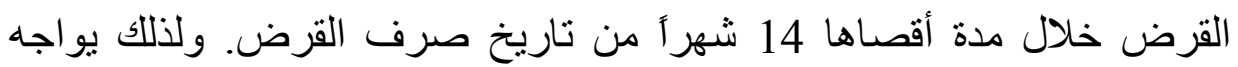

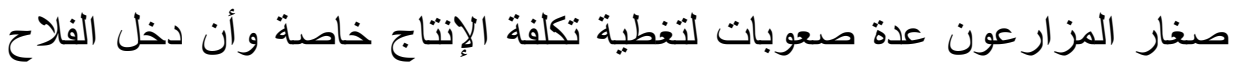

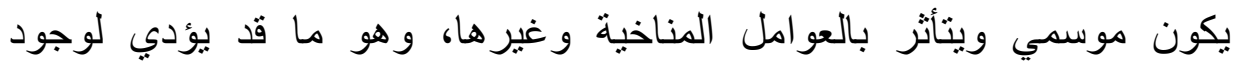

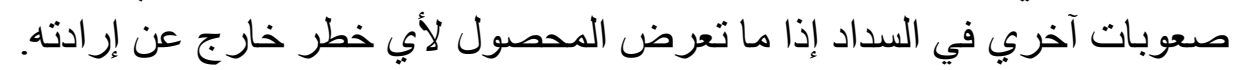
(2- 3) ارتفاع أسعار الفائدة على القروض الزراعية من وجهة نظر المزارعين. بالرغم من قيام الدولة بدعم أسعار الفائدة بالنسبة لقروض الإنتاج الزراعي، إلا أن عملية إنتاج المحاصيل الزراعية عملية تتسم بعدم الاستقرار نتيجة الارتباط بعوامل الجو المتقلب ( عبدالمجيد واخرون، 2014)، وكذلك لإنة 
أسعار المنتجات الزراعية، وهو ما يؤدى إلى عجز عدد كبير من المزارعين عن الدئ

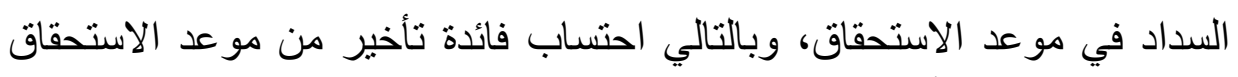

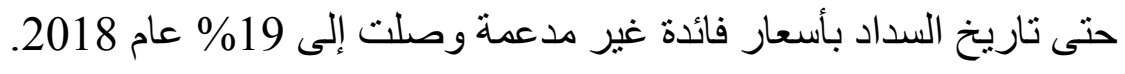

(2- 4) عدم تقديم القدر الكافي من الخدمات الإرشادية الزراعية للمزارعين.

لا تقتصر أهداف السياسة الائتمانية على مجرد تقديم الخدمات الائتمانية

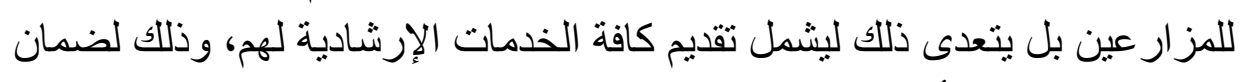
تحقيق الاستخدام الأمثل للموارد الإنتاجية الزراعين.

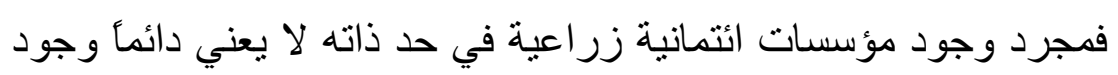

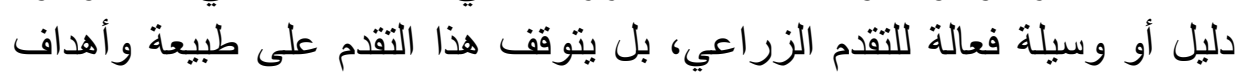

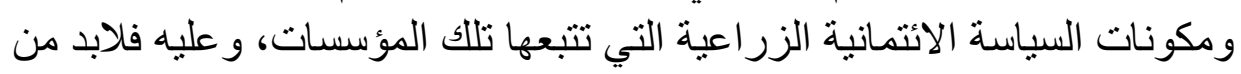

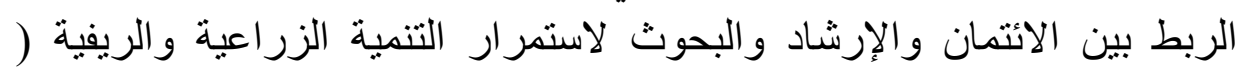

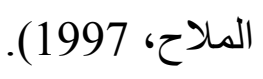

(2- 5) عدم مقدرة معظم المزارعين على الالتزام بسداد القرض في موعده. يختلف النشاط الزراعي عن الأنثطة الاقتصادية الأخرى حيث تثتأثر إنتاجيته

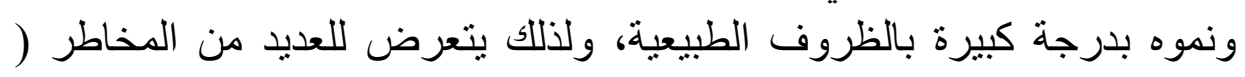

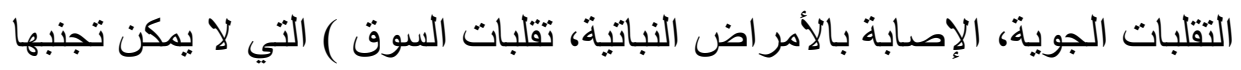

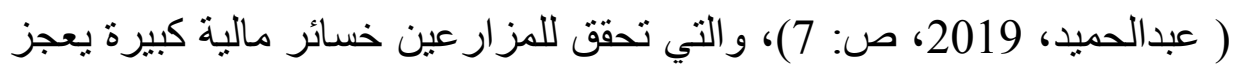

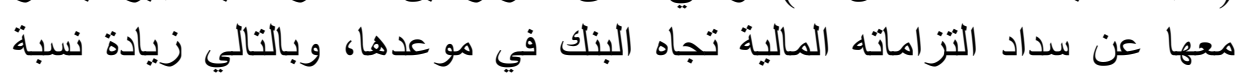

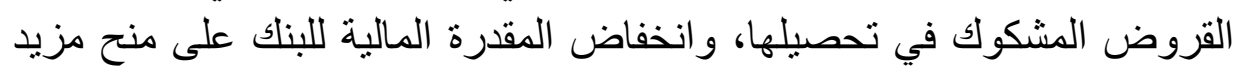

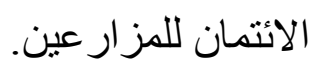

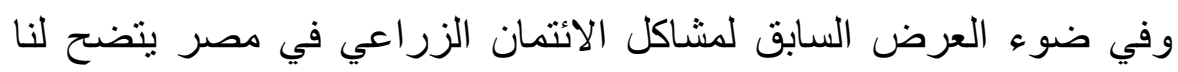

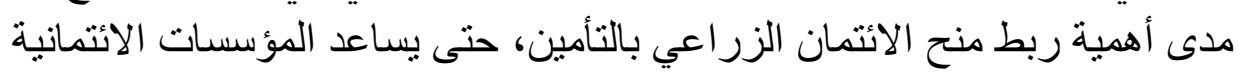

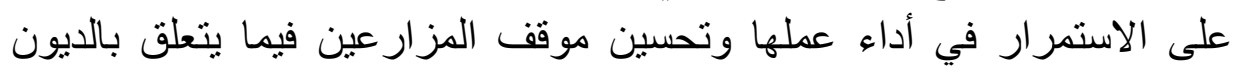

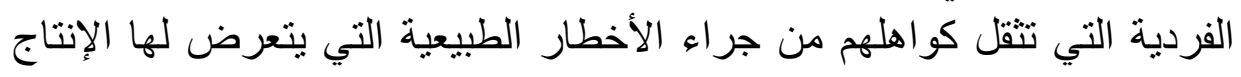
من حين لآخر. 


\section{3. التوزيعات الاحتمالية المستخدمة في تسعير تأمين الايتمان.}

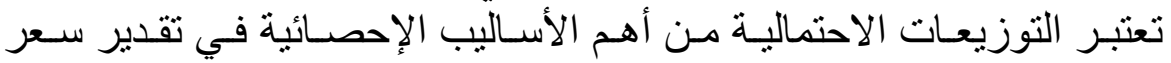

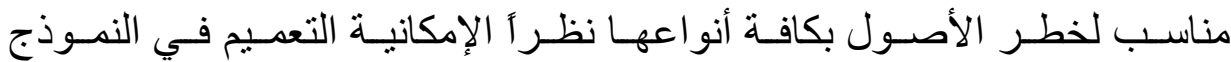

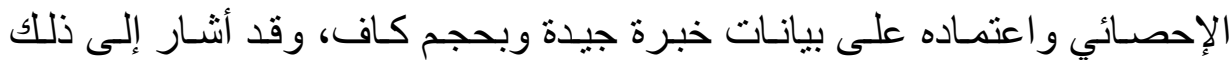
العديد من الكتاب في مجال التأمينات العامة (Salem M., 2012).

ويعتبر تقدير العدد المتوقع، وكذلك حجم الخسارة المتوقعة من أهم العناصر

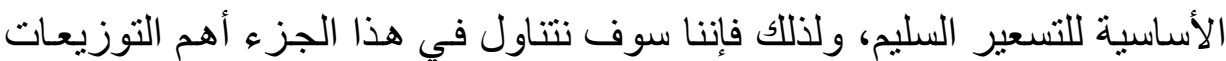

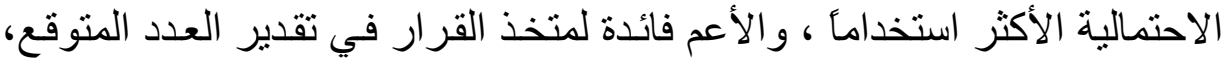
وحجم الخسارة المتوقعة من خلال نقطتين أساسيتين وهما: 1- التوزيعات الاحتمالية المناسبة لعدد الحوادث.

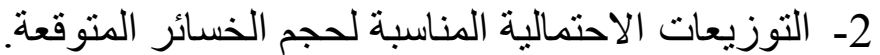

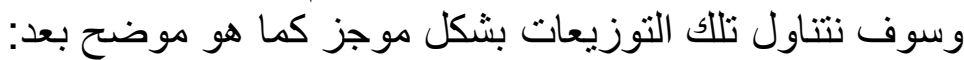

\section{(1-3) التوزيعات الاحتمالية المناسبة لعدد الحوادث.}

تستخدم التوزيعات الاحتمالية المنفصلة في تقدير عدد الحوادث المتوقعة ،

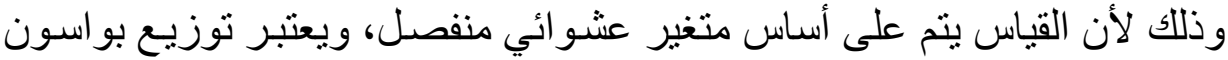
وذي الحدين السالب من أكثر التوزيعات ملاءمة واستخدامأ لعدد الحوادث. وسيتم فيما يلي عرض لتلك التوزيعات:

\section{Poisson Distribution (1-1-3) توزيع بواسون}

يستخدم توزيع بو اسون إذا كان لدينا متغير أ عشو ائياً متقطعاً يمثل ظاهرة

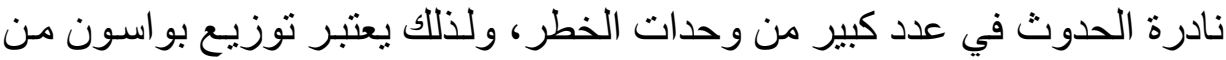

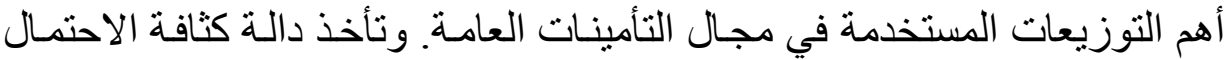
لتوزيع بواسون الثنكل الثالي (Graybill A., 1974, p.94 ): $f(x)=\frac{e^{-\lambda} \lambda^{x}}{x !} ;$ for $x=0,1,2, \ldots .$. 
ومن أهم خصائص توزيع بواسون أن القيمة المتوقعة تساوي التباين أي:

$\mu=\sigma^{2}=n * p$

Negative Binomial توزيـع وذي الحـين السـالب (2-1-3)

Distribution

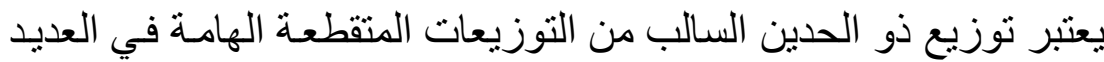

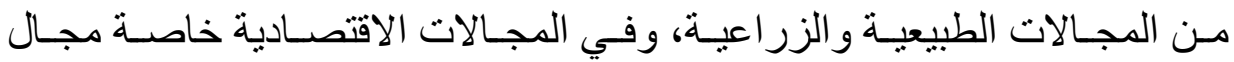

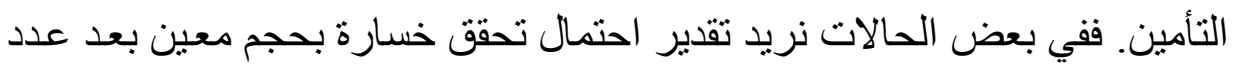

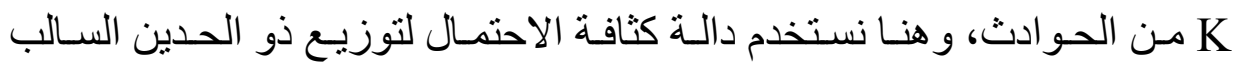

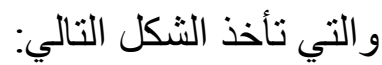

$$
\begin{array}{r}
f(x)=\left(\begin{array}{l}
x+r-1 \\
x
\end{array}\right) * p^{r} *(1-p)^{x} ; \text { for } x=0,1,2, \ldots . ., n \\
\text { ومعالم التوزيع هي: }
\end{array}
$$

$$
\begin{gathered}
\mu=\frac{r(1-p)}{p} \\
\sigma^{2}=\frac{r(1-p)}{p^{2}}
\end{gathered}
$$

(2-3) التوزيعات الاحتمالية المناسبة لحجم الخسائر المتوقعة.

تســخدم التوزيعـات الاحتماليـة المتصــلة لقيـاس حجـم الخســارة الماليـة

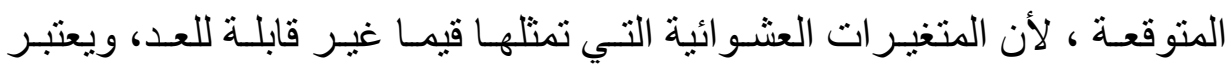

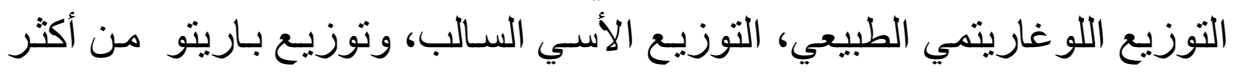

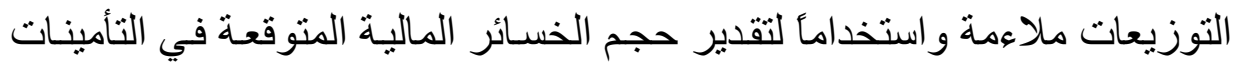

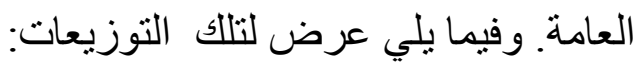




\section{The log - normal التوزيع اللوغاريتمي الطبيعي (1-2-3)}

\section{.Distribution}

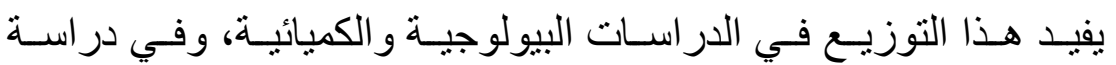

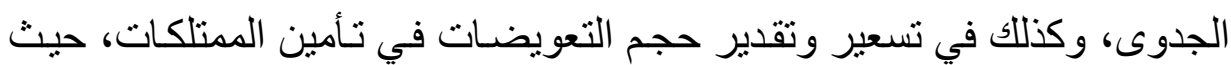

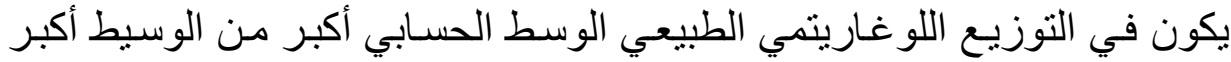

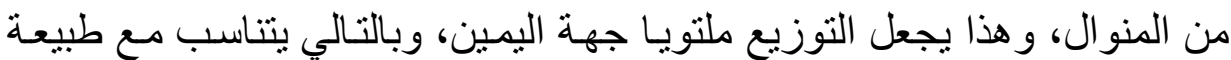

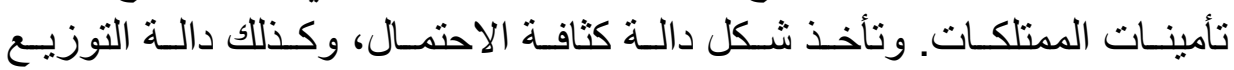
التر اكمي لهذا التوزيع الثكل التالي (Samir K., 2007, p.155):

$f(x)=\frac{1}{\sigma x \sqrt{2 \pi}} \times \exp ^{\left(\frac{-(\ln x-\mu)^{2}}{2 \sigma^{2}}\right)}$

$$
\boldsymbol{x}>\mathbf{0}, \quad-\infty<\mu<\infty, \quad \sigma>\mathbf{0}
$$

$\boldsymbol{F}(x)=\int \frac{1}{\sigma x \sqrt{2 \pi}} \times \exp ^{\left(\frac{-(\ln x-\mu)^{2}}{2 \sigma^{2}}\right)}$

ونظر أ لصعوبة تكامل الدالة السابقة فلقد تم التوصل للدالة التالية:

$z=\frac{\ln x-\mu}{\sigma}$

حيث يؤول التوزيع اللو غاريتمي إلى التوزيع الطبيعي في حال استخدام

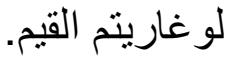
ويكون منوسط وتباين التوزيع كما يلي:

$\mu=\boldsymbol{e}^{\mu+\sigma^{2} / 2}$

$v=e^{2 \mu+\sigma^{2}} \times\left(e^{\sigma^{2}}-1\right)$ 


\section{(2-2-3) التوزيع الأسي السالب Negative exponential}

في بعض الحالات تكون قيم المتغيرات العشوائية متصلة و لا تتوزع

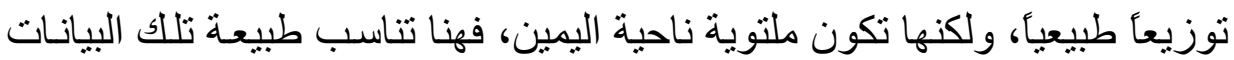

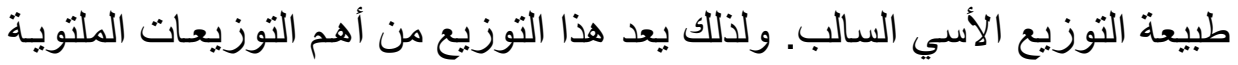

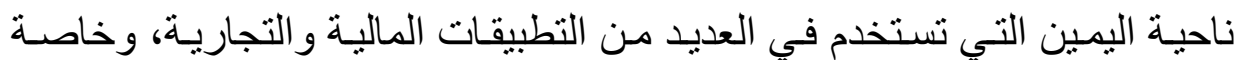

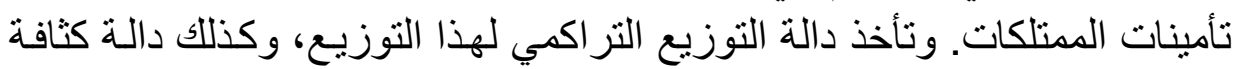

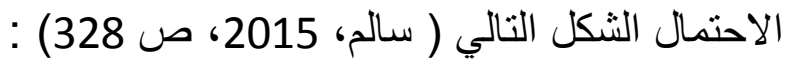

$$
\begin{array}{ll}
F(x)=1-e^{-\lambda x} & x \geq 0 \\
f(x)=\lambda e^{-\lambda x} & x \geq 0
\end{array}
$$

حيث أن متوسط وتباين هذا التوزيع:

$$
\mu=\frac{1}{\lambda} \quad, \quad v=\frac{1}{\lambda^{2}}
$$

Pareto distribution توزيع باريتو

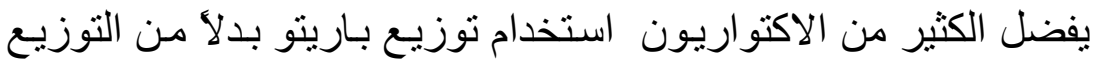

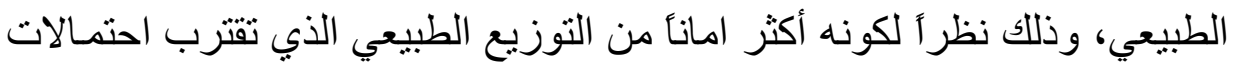

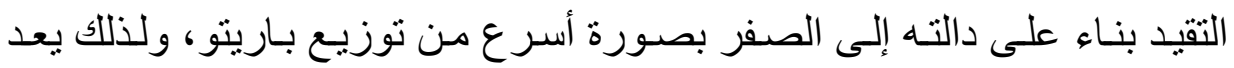

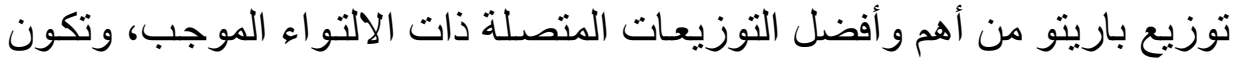

دالة التوزيع التر اكمي ودالة كثافة الاحتمال كما يلي (Weisstein: 2005 ) :

$$
\begin{aligned}
& F(x)=1-\left(\frac{\lambda}{x}\right)^{\alpha} \quad x \geq \lambda \\
& f(x)=\frac{\alpha}{\lambda}\left(\frac{\lambda}{x}\right)^{\alpha+1} \quad x \geq \lambda
\end{aligned}
$$


ويقدر الوسط الحسابي و التباين كما يلي:

$\mu=\frac{\alpha \lambda}{\alpha-1}$

$v=\frac{\alpha \lambda^{2}}{\alpha-2}-\left(\frac{\alpha \lambda}{\alpha-1}\right)^{2}$

نلاحظ أن أقصى قيمة للدالة عندما x x ، وللحصول على الكنوسط

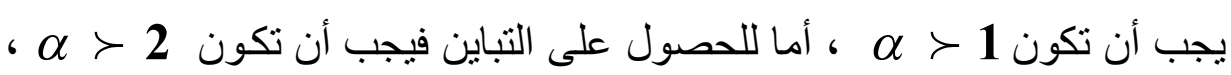
وفي عكس ذللك فإن قيمة

\section{4. تحديـد التوزيـع الاحتمـالي المناسـب لتسـعير تـأمين الائتمـان}

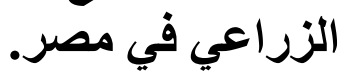

في هذ الجزء سيتم اختبار التوزيعات السابق تناولها بالجزء الثالث لمعرفة التهاء

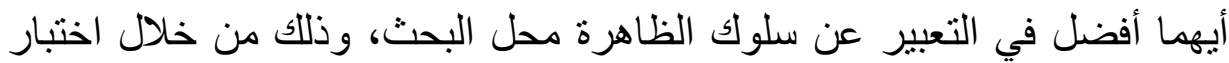

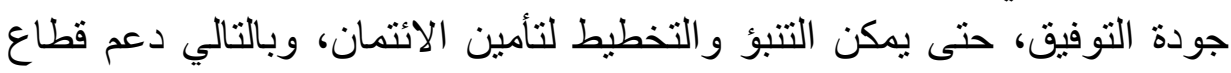

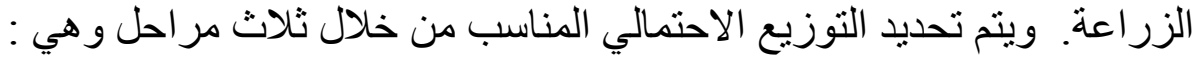

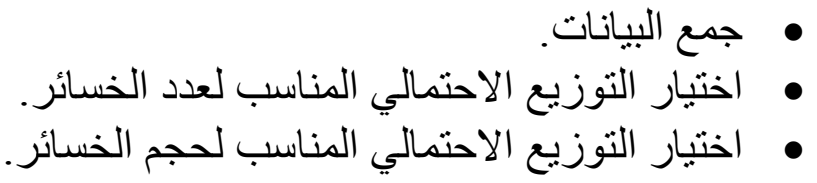

(1-4) (1-4) (لبيانات

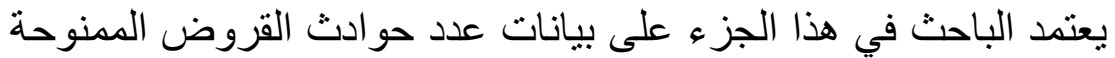

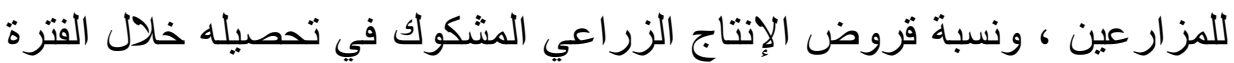

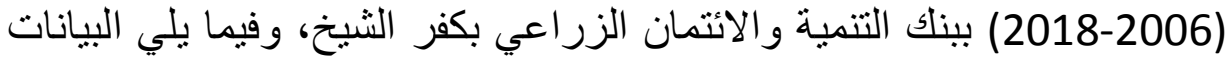

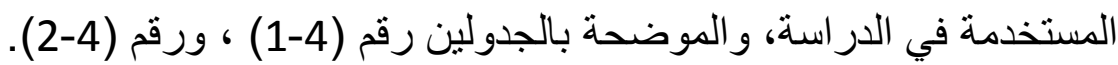




$$
\text { جدول (4-1) التوزيع التكراري لعدد الحو ادث }
$$

\begin{tabular}{|c|c|}
\hline عدا عدد القروض الممنوحة الحو ادث & 0 \\
\hline 57320 & 1 \\
\hline 5630 & 2 \\
\hline 23 & 3 \\
\hline 16 & 4 \\
\hline 0 &
\end{tabular}

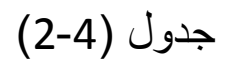

بيان بالمنح الزر اعية و المسدد زر اعي و المستحق 1006 ونسبة المستحق عن

\begin{tabular}{|c|c|c|c|c|}
\hline نسبة المستحق زراعي & الرصيد المستحق & المسدد زراعي & المنح زراعي & السنة \\
\hline 0.088071895 & 24255000 & 251145000 & 275400000 & 2006 \\
\hline 0.088071625 & 26854800 & 278065200 & 304920000 & 2007 \\
\hline 0.088069257 & 29837600 & 308959400 & 338797000 & 2008 \\
\hline 0.088073217 & 33154370 & 343286630 & 376441000 & 2009 \\
\hline 0.081351497 & 31355470 & 354076530 & 385432000 & 2010 \\
\hline 0.074936223 & 29556570 & 364866430 & 394423000 & 2011 \\
\hline 0.086949855 & 38882149 & 408296851 & 447179000 & 2012 \\
\hline 0.268798993 & 110531490 & 300673510 & 411205000 & 2013 \\
\hline 0.272357864 & 104727046 & 497849000 & 384520000 & 2014 \\
\hline 0.118832303 & 44640543 & 331019457 & 375660000 & 2015 \\
\hline 0.154058137 & 51580667 & 283232333 & 334813000 & 2016 \\
\hline 0.091492417 & 27676822 & 274827178 & 302504000 & 2017 \\
\hline 0.062045666 & 17493217 & 264447783 & 281941000 & 2018 \\
\hline
\end{tabular}
الفترة من عام 2006 وحتى 2018

المصدر: بنك التنمية والائتمان الزراعي بكفر الثيخ. 


\section{(2-4) اختيار التوزيع الاحتمالي المناسب لعدد الخسائر.}

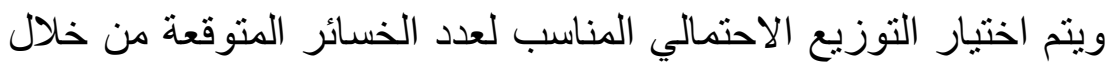

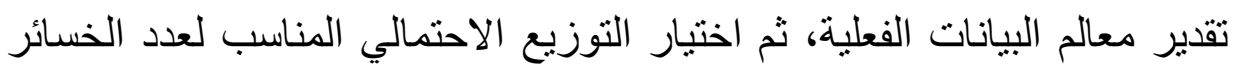

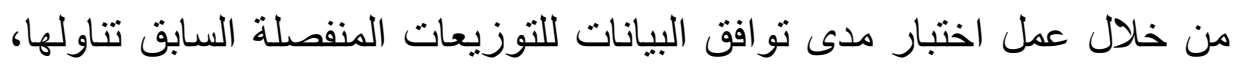

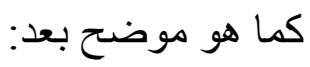

\section{(1-2-4) تقدير المعالم الاحصائية للبيانات الفعلية.}

و هنا نقوم بتقدير متوسط وتباين البيانات الواردة بجدول (4-1) التوزيع

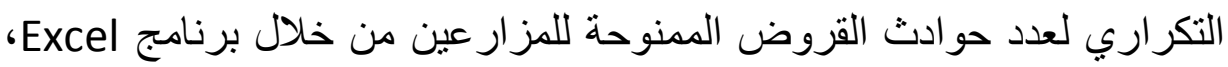

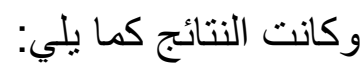

$$
\begin{aligned}
& \bar{x}=\sum x \cdot p(x)=0.090873 \\
& \sigma^{2}=\sum x^{2} \cdot p(x)-\left(\sum x \cdot(p)\right)^{2}=0.09313
\end{aligned}
$$

(2-2-4) اختيار التوزيع الاحتمالي المناسب لعدد الخسائر المالية في تأمين الائتمان.

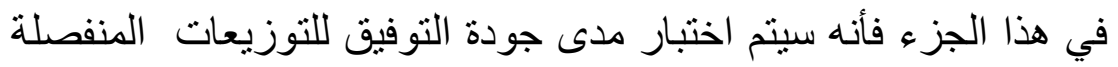
لاختبار التوزيع المناسب لعدد الخسائر المالية المتوقعة بتأمين الاتئمان كما يلي: لئي:

$$
\text { (1-2-2-4) توزيع بواسون }
$$

يمكن أن تتوزع بيانات الائتمان الزر اعي طبقا لدالة بو اسون وصيغته:

$$
f(x)=\frac{e^{-\lambda} \lambda^{x}}{x !} ; \text { for } x=0,1,2, \ldots . .
$$

ومن أهم خصائص توزيع بو اسون أن القيمة المتوقعة تساوي التباين أي: 
$\mu=\sigma^{2}=\lambda=n * p=0.090873$

ولتحديد ما إذا كانت هذه البيانات تتبع توزيع بواسون من عدمه يتم

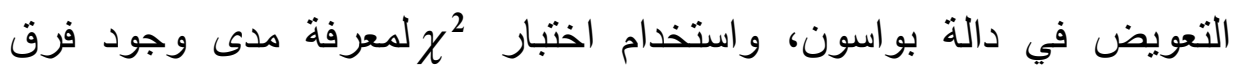
معنوي، وذللك كما يلي:

$$
\text { جدول (3-4) }
$$

اختبار $\chi^{2}$

\begin{tabular}{|c|c|c|c|c|}
\hline$\chi^{2}$ & الفرق & لبو اسون & تركمي مشاهد & كش. نسبي \\
\hline 1.07533E-05 & -0.0031335 & 0.91313371 & 0.91000015 & 0.91000015 \\
\hline $1.0721 \mathrm{E}-05$ & 0.0032679 & 0.99611292 & 0.99938084 & 0.08938068 \\
\hline $1.88331 \mathrm{E}-08$ & -0.0001372 & 0.99988321 & 0.99974598 & 0.00036514 \\
\hline $6.66316 \mathrm{E}-12$ & 0.0000025 & 0.99999741 & 1 & 0.00025401 \\
\hline $2.14931 \mathrm{E}-05$ & & & & \\
\hline
\end{tabular}

وحيث أن خ الجدولية بدرجات حرية (3، 1\%) تساوي 11.34 أما .

المحسوبة تساوي 2.14931E-05 أي أن الجدولية أكبر من المحسوبة وبالتالي يمكن القول بانه لا يوجد فرق معنوي، وأن البيانات تتبع توزيع بو اسون.

\section{(2-2-2-4) توزيع ذي الحدين السالب}

رغم أننا قبلنا أن البيانات تتوزع طبقأ لصيغة توزيع بو اسون فإننا نجري

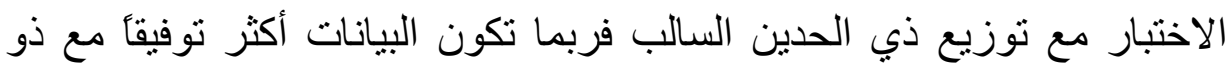

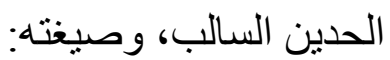




$$
\begin{aligned}
& f(x)=\left(\begin{array}{l}
x+r-1 \\
x
\end{array}\right) * p^{r} *(1-p)^{x} ; \text { for } x=0,1,2, \ldots . ., n \\
& \text { ومعالم التوزيع هي: }
\end{aligned}
$$

$$
\begin{gathered}
\mu=\frac{r(1-p)}{p}=0.090873 \\
\sigma^{2}=\frac{r(1-p)}{p^{2}}=0.09313
\end{gathered}
$$

وبقسمة المعادلة الأولى على المعادلة الثانية نحصل على:

$$
p=0.975765
$$

$$
(1-p)=0.0242349
$$

وبالتعويض بقيمة

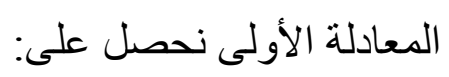

\section{$r=36.588$}

\begin{tabular}{|c|c|c|c|c|}
\hline$\chi^{2}$ & الفرق & التر اكمين لذو & تركمي مشاهد & كشاهدبي \\
\hline 0.50248715 & 0.50248715 & 0.407513 & 0.91000015 & 0.91000015 \\
\hline
\end{tabular}

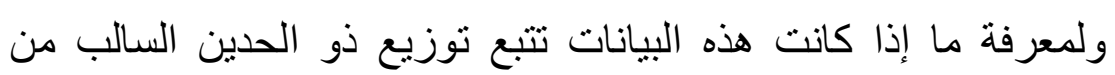

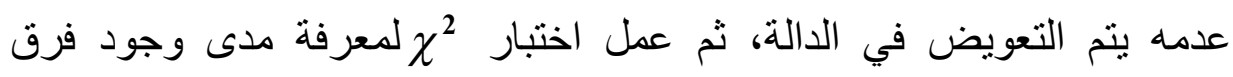
معنوي، وذللك كما يلي:

$$
\text { جدول (4-4) }
$$

اختبار $\chi^{2}$ للديون المستحقة من خلال ذو الحدين السالب 


\begin{tabular}{|r|r|c|c|c|}
\hline 0.64789284 & 0.64789284 & 0.351488 & 0.99938084 & 0.08938068 \\
\hline 0.83514698 & 0.83514698 & 0.164599 & 0.99974598 & 0.00036514 \\
\hline 0.948702 & 0.948702 & 0.051298 & 1 & 0.00025401 \\
\hline 2.93423 & & & & \\
\hline
\end{tabular}

وحيث أن ح الجدولية بدرجات حرية (3، 1\%) تساوي 11.34 أما X المحسوبة تساوي 2.93423 أي أن المحسوبة أصغر من الجدولية، وبالتالي لا يوجد فرق معنوي، و يمكن القول بأن البيانات تتبع توزيع ذو الحدين السالب. وبمقارنة النتائج المتحصل عليها من توزيع بواسون وتوزيع ذو الحدين

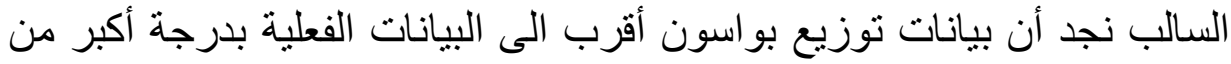
توزيع ذو الحدين السالب.

\section{(3-4) اختيار التوزيع الاحتمالي المناسب لحجم الخسائر.}

و هنا سيتم اختيار التوزيع الاحتمالي المناسب لقياس حجم الخسائر

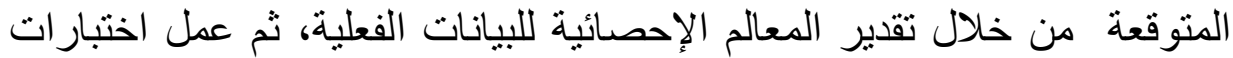
جودة التوفيق للتوزيعات المتصلة السابق تناولها، كما هو موضح بعدة لإحدان

\section{(1-3-4) تقدير المعالم الاحصائية للبيانات الفعلية.}

وفي هذا الجزء فإننا سوف نقوم بتقدير المعالم الاحصائية للبيانات الفعلية

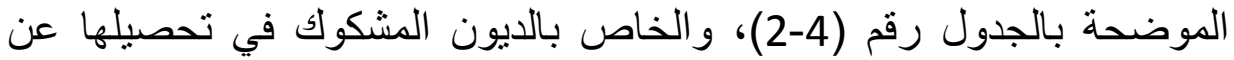
الفترة من عام 2006 وحتى 2018.

جدول(4-5) التوزيع التكراري لنسب الديون المستحقة

\begin{tabular}{|c|c|}
\hline فئة نسبة المستحق \% & \% \\
\hline 9 & -10.2 \\
\hline 1 & -14.62 \\
\hline 1 & التكرار \\
\hline
\end{tabular}




\begin{tabular}{|c|c|}
\hline 0 & -18.83 \\
\hline 2 & -23.04 \\
\hline 13 & المجموع \\
\hline
\end{tabular}

وهنا تم استخدام برنامج Excel في تقدير المتوسط x وكانت النتائج كما يلي: ت ولنا

$$
\begin{aligned}
\bar{x} & =\sum x \cdot p(x)=\quad 11.8819231 \\
\sigma^{2} & =\sum x^{2} \cdot p(x)-\left(\sum x \cdot(p)\right)^{2} \\
& =179.3249-141.1801=38.1448
\end{aligned}
$$

(2-3-4) اختيار التوزيع الاحتمالي المناسب لقياس حجم الخسائر المالية في تأمين الائتمان.

في هذا الجزء فأنه سيتم اختبار ات جودة التوفيق للتوزيعات المتصلة لاختيار التوزيع المناسب لقياس حجم الخسائر المالية المتوقعة بتأمين الائتمان كما يلي:

The log - normal التوزيـع اللوغـاريتمي الطبيعـي (1-2-3-4) .Distribution

$$
\begin{aligned}
& \boldsymbol{f}(\boldsymbol{x})=\frac{1}{\sigma \boldsymbol{x} \sqrt{2 \pi}} \times \boldsymbol{e}^{\frac{-1}{2 \sigma^{2}}(\ln x-\mu)^{2}} \\
& \boldsymbol{x}>\mathbf{0}, \quad-\infty<\mu<\infty, \quad \sigma>\mathbf{0} \\
& \mu=e^{\mu+\sigma^{2} / 2}=\mathbf{1 1 . 8 8 1 9 2 3 1}
\end{aligned}
$$




$$
\sigma^{2}=e^{2 \mu+\sigma^{2}} \times\left(e^{\sigma^{2}}-1\right)=38.1448
$$

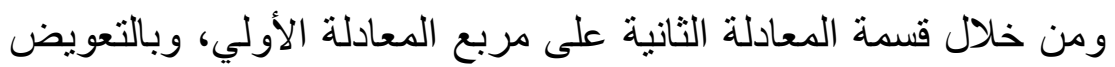

بقيمة م في معادلة المتوسط نجد أن القيمة المتوقعة لنسبة الديون المستحقة:

$$
\mu=1.98591
$$

ومن ثم يتم استخدام اختبار كولومنجروف سميرنوف لحساب قيمة

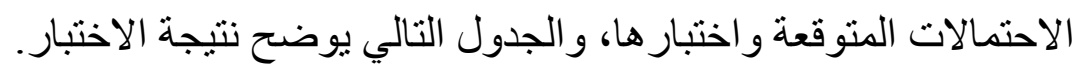

جدول (4-6) اختبار كولمجروف للديون المستحقة من خلال التوزيع

\begin{tabular}{|c|c|c|c|c|}
\hline الفرق المطلق & الفرق & اللت غاريتمي & تركمي مشاهد & ك. نسبي مشاهد \\
\hline 0.085907692 & 0.085907692 & 0.6064 & 0.692307692 & 0.692307692 \\
\hline 0.097269231 & -0.09726923 & 0.8665 & 0.769230769 & 0.076923077 \\
\hline 0.109246154 & -0.10924615 & 0.9554 & 0.846153846 & 0.076923077 \\
\hline 0.138446154 & 0.138446154 & 0.9846 & 0.846153846 & 0 \\
\hline 0.0055 & 0.0055 & 0.9945 & 1 & 0.153846154 \\
\hline
\end{tabular}
اللو غاريتمي الطبيعي

وحيث أن أكبر فرق مطلق هو 0.138446154 ، و هذه القيمة أصغر من

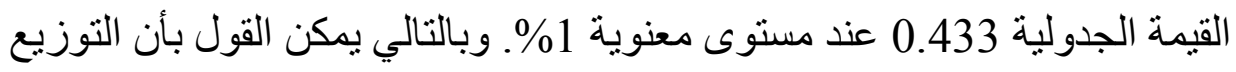

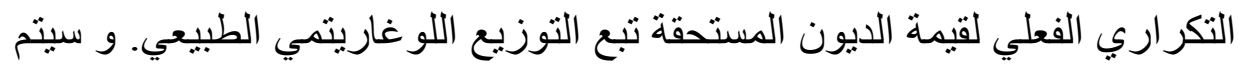
عمل الاختبار ات الباقية لاختيار أقربها للقيمة الفعلية.

(2-2-3-4) التوزيع الأسي السالب Negative exponential . 


$$
\begin{aligned}
& f(x)=\lambda e^{-\lambda x} \quad x \geq 0 \\
& \mu=\frac{1}{\lambda}=11.8819231 \\
& v=\frac{1}{\lambda^{2}}=38.1448 \\
& \therefore \lambda=0.0841615 \\
& \text { جدول (7-7) }
\end{aligned}
$$

اختبار كولمجروف للايون المستحقة من خلال التوزيع الأسي السالب

\begin{tabular}{|r|r|r|r|r|}
\hline & تركمي مشاهد & & \\
\hline 0.189445 & 0.189445 & 0.502862577 & 0.692307692 & 0.692307692 \\
& & & & \\
\hline 0.11806 & 0.11806 & 0.651170482 & 0.769230769 & 0.076923077 \\
& & & & \\
\hline 0.090919 & 0.090919 & 0.755234615 & 0.846153846 & 0.076923077 \\
\hline 0.0179 & 0.0179 & 0.828253945 & 0.846153846 & 0 \\
\hline 0.119551 & 0.119551 & 0.880449453 & & 0.153846154 \\
\hline
\end{tabular}

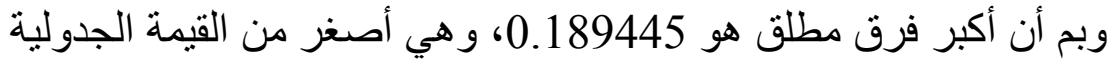

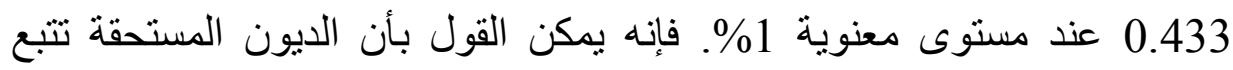
التوزيع الأسي السالب. ومع ذللك فإنة سيتم عمل باقي الاختبار اتل لانيات لاختبار اقربها

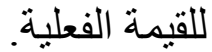

\section{. Pareto distribution توزيع باريتو}

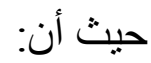




$$
\begin{aligned}
& \boldsymbol{f}(\boldsymbol{x})=\frac{\alpha \lambda^{\alpha}}{\boldsymbol{x}^{\alpha+1}} \quad \boldsymbol{x} \geq \lambda \\
& \mu=\frac{\alpha \lambda}{\alpha-\mathbf{1}}=\mathbf{1 1 . 8 8 1 9 2 3 1} \\
& v=\frac{\alpha \lambda^{2}}{\alpha-2}-\left(\frac{\alpha \lambda}{\alpha-1}\right)^{2}=\mathbf{3 8 . 1 4 4 8}
\end{aligned}
$$

ومن خلال قسمة المعادلة الثانية على مربع المعادلة الأولي نتوصل إلى ه

$$
\begin{aligned}
& \alpha=\mathbf{2 . 3 3} \\
& \lambda=\quad 6.78237
\end{aligned}
$$

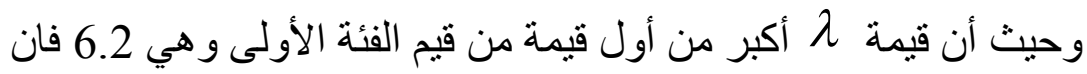

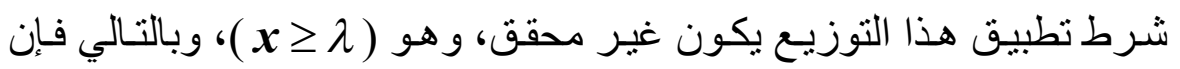
توزيع باريتو يكون غير مناسب لهذه البيانات.

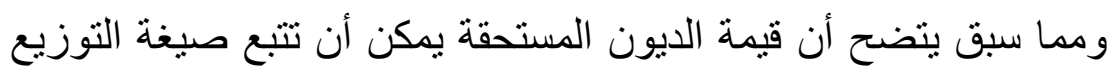

\begin{tabular}{|c|c|}
\hline كولومنجروف & التوزيع \\
\hline 0.189445 & الأسى السالب \\
\hline 0.138446154 & اللو غاريتمي الطبيعي \\
\hline 0.433 & القيمة الجدولية \\
\hline
\end{tabular}

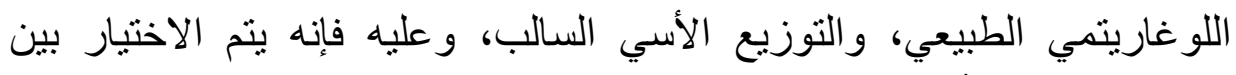

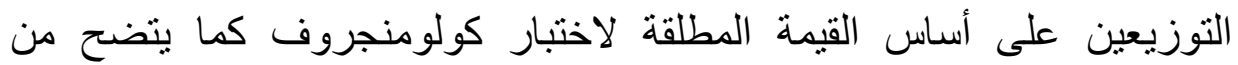

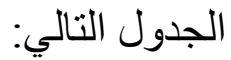

جدول (4-8) مقارنة بين قيم الاختبار لكلا التوزيعين 
ومن خلال النتائج السابقة يمكن استخدام التوزيع اللو غارينمي الطبيعي

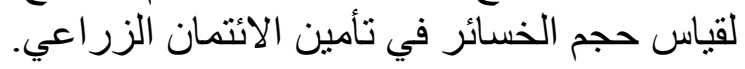

\section{النتائج والتوصيات}

بعد القيام بذلك البحث ومن خلال البيانات موضع الدراسة وتحليلها قد

\section{أولا: النتائج} توصل الباحث لعدة نتائج أهمها:

(1)رغم ضرورة الائتمان الزراعي لمساعدة المزارعين على عملية

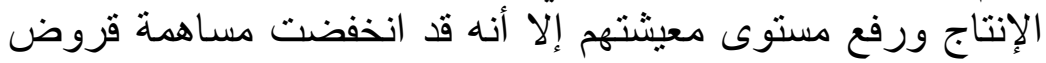

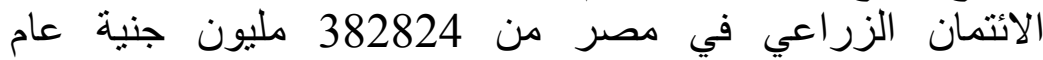
2008/2007 إلى 27375 مليون جنية عام الإن $2015 / 2016$.

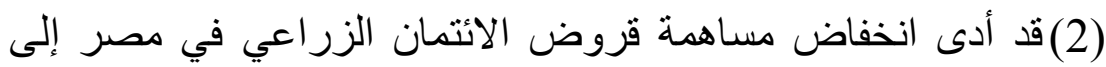

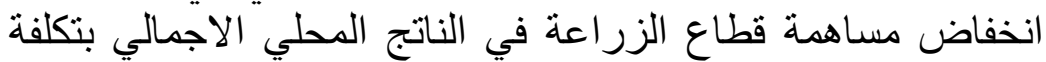

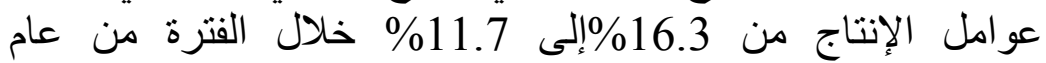
2008/2007م إلى عام 2016 من م.

(3) اتضح أن طبيعة البيانات الخاصة بعدد الحوادث تنتو افق بشكل كبير

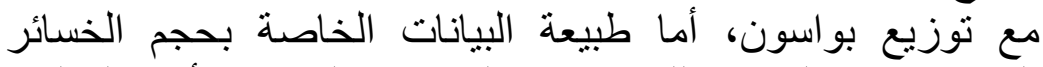

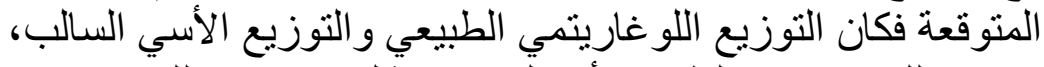

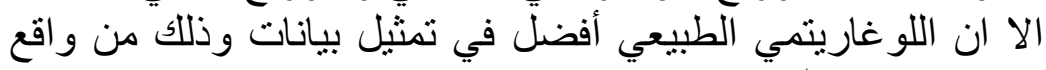

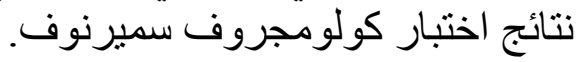

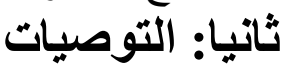

من خلال النتائج التي تم التوصل اليها و السابق ذكرها يمكن للباحث

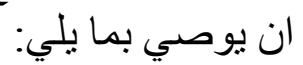

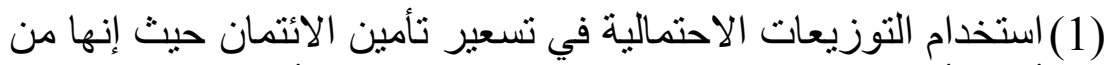

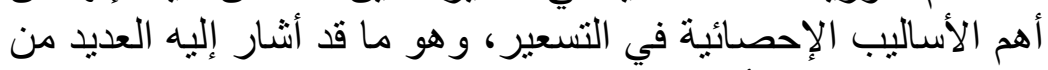
الكتاب في مجال التأمينات ألعامة. 


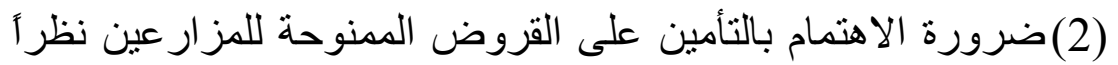

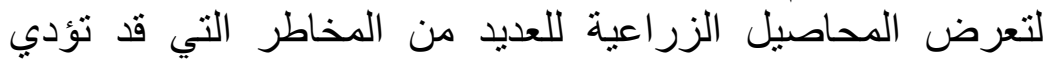
بالمز ارع إلى عدم القدرة على سداد القرض و الفو الئد المستحقة عليه.

(3)ضرورة عمل المزيد من الأبحاث و الدراسات المتعلقة بتأمين الاتتمان نظر ألافتقار المكتبة العربية لتأك الأبحاث رغم أهميتها.

\section{قائمة المراجع}

\section{أولا: المراجع العربية}

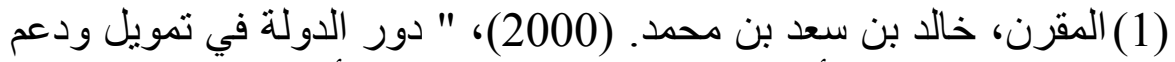

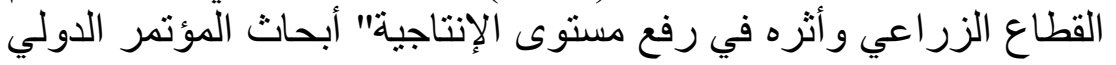
في اقتصاديات الزر راعة في العالم الإسلامي، مطبعة مركز صالح كالح كامل.

(2) الملاح، جلال. (1997)، "الربط بين الايتمان والإرشاد و البحوث" الإثمان

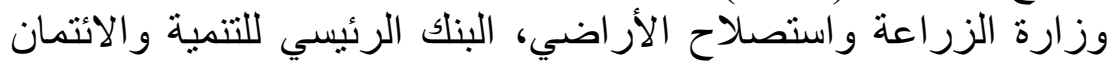

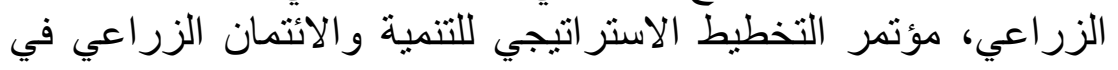
مصر.

(3)حسن، رشا سامح عيسى. (2015)، " أثز القروض و المنح الأجنيبة على الفي

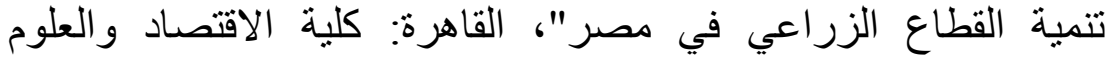

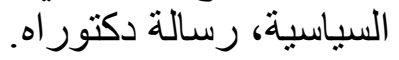

(4)حشيش، إجلال هانم محمد عبداللطيف. (2003)، " دراسة تحليلية

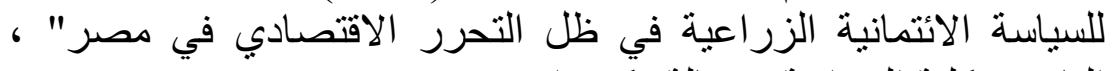
القاهرة: كلية الزر اعة، رسالة دكتور الزاه.

(5) سالم، محمود (2015)، "رياضيات التأمينات العامة - النماذج الرياضية و الاحصائية وتطبيقاتها"، كفر الثيخ ،مكتنة كلية التجارة. 
(6) سمايل، خديجة قادر ، عثمان، صابر بيردأود ، (2015)، " تقدير وتحليل

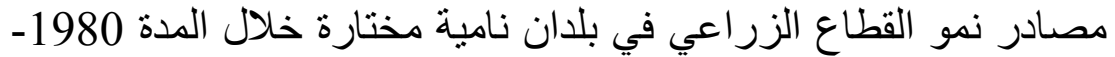

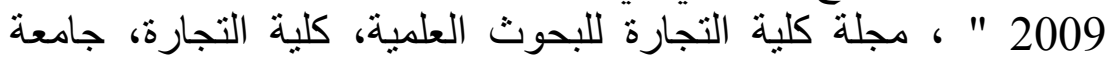
الاسكندرية، العدد الأولـ المجلد الثاني و الخمسون.

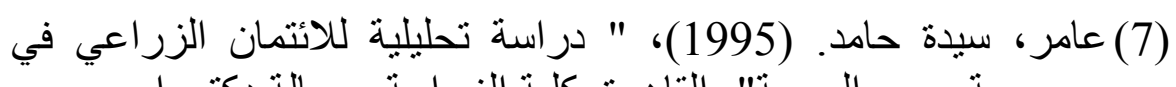
جمهورية دصر العربية"، القاهرة: كلية الزراعة، رسالة دالة دكتوراه.

(8) عبدالحميد، نها عبداللطيف. (2019)، " تسعير تأمين المحاصيل

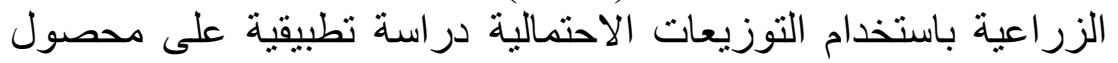
القمح بمصر" مجلة الدراسات التجارية المعاصرة، كلية التجارة، جالية جامعة كفر الثيخ، العدد السادس.

(9) عبدالمجيد، عبدالفتاح عبدالرحمن. وآخرون (2014)، " دور التنمية

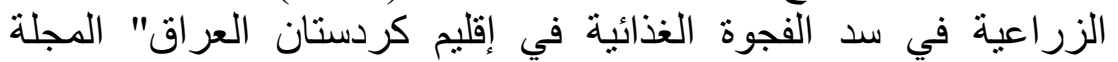

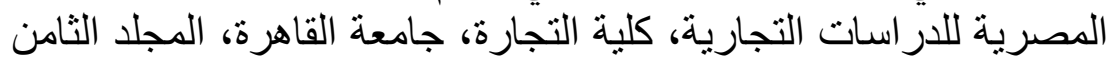

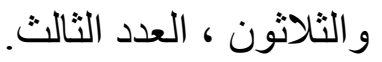

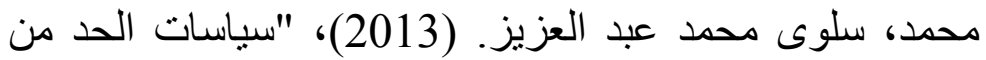

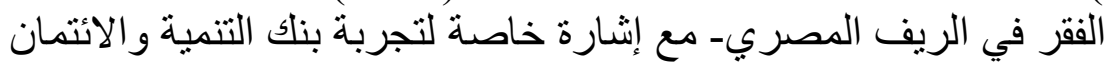

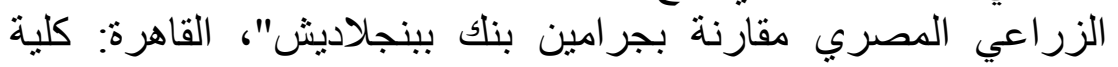
الاقتصاد و العلوم السياسية، رسالة دكتور اهن.

\section{ثانيا: المراجع الأجنبي}

(1)Ashour , S. k., S. Salem (2007) "Probability distributions", Cairo University.

(2) Asseldonk V. Marcel, Bertrand Muller \&, Elodie M. (2018) " Linking crop insurance and rural credit " Development Economics Group, Wageningen UR, The Ne therlands CIRAD, Montpellier, France. 
(3) Carter A., Carolina T. (2006) "Can Insurance Unlock Agricultural Credit and Promote Economic Growth" https://www.researchgate.net.

(4) Carter, M.R., L. Cheng, (2016) "Where and How Index Insurance Can Boost the Adoption of Improved Agricultural Technologies" University of California.

(5)Carter, M.R., F. Galarza, and S. Boucher., (2007) "Underwriting Area-based Yield Insurance to Crowdin Credit Supply and Demand", Savings and Development, University of California.

(6) Graybill, Franklin A., Boes, Does C., (1974) "Introduction to the theory of statistics" Library of Congress Cataloging in Publication Data, ISBN 0-07042864-6

(7) Hossack, I.B., Pollard, J.H., \& Zehnwirth, B.,(1999) “ Introductory statistics with applications in general insurance", Cambridge University Press

(8) Saddik , Ibrahim (1995) “ Credit and Investment in Egyptian Agriculture " Faculty of Agriculture, Menoufeya University, Cairo.

(9) Salem, M.,(2012) "Mathematical Models and Statistical Tools are to Satisfy Requirements Equity and Effuciency of the cost of insurance. JRL of the faculty of commerce for Scientific Research. 
(10) Naranjo, Maria A., Janneke P. \& Francisco A. (2016) “ Credit, Insurance and Farmers' Liability: Evidence from a Lab in the Field Experiment with" The Environment for Development (EFD), Swedish International Development Cooperation Agency.

(11) Nour, M. (1992) "Agricultural Credit in A.R.E.", Food and Agriculture Organization, Cairo.

(12) Weisstein, EW ( 2005), "Pareto Distributionfrom Wolfram Math World" Cited by 43- Related articles, mathworld.wolfram.com. 